\title{
The usefulness of reflexive photography for qualitative research: a case study in higher education
}

\author{
S. Schulze \\ Department of Further Teacher Education \\ University of South Africa \\ Pretoria, South Africa \\ e-mail: schuls@unisa.ac.za
}

\begin{abstract}
This study explores the usefulness of reflexive photography for qualitative research in the human and social sciences. The investigation was done in the context of how male academics construct their world in a university during transformation. A group of white, male academics in the human sciences were provided with a camera and were requested to take pictures of the most meaningful aspects of their work environment. Thereafter photo-elicitation interviews were conducted, transcribed and analysed. The study illustrates the usefulness of reflexive photography to determine human interpretation of interaction with the environment. Participants commented positively on and helped to identify the advantages and limitations of the technique. The research indicated that photographs have no intrinsic meaning but serve as symbols of meaning that participants explain during interviews. Content analysis, a second level of analysis that is based on the first level, is useful in some ways as indicated.
\end{abstract}

\section{INTRODUCTION AND BACKGROUND}

This study explores the usefulness of reflexive photography for qualitative research in the human and social sciences. The investigation was done in the context of how white, male academics construct their world in a distance education university during a time of great transformation. For example: in order to address racial imbalances, employment equity practices at the university place white males last in line for employment or promotion; and white males in management positions are replaced by managers from other racial groups. In addition, the institution merged with two other Higher Education (HE) institutions. The merger added about 60,000 new registrations to the university's 181,000 students and about 1000 members to its staff of 3500 . The merger caused significant changes to institutional culture since many non-academic certificate courses (previously offered by a distance education technikon) were added to the institution's menu. The university's culture also changed in other ways as it was influenced by a new (predominantly black) management team. For example, the names of some buildings were changed to names of (black) political icons and the university 
received a new logo and branding that are more African and less European.

Within this changed environment, the aim of the article is to offer a new paradigm to capture the everyday experiences and perceptions of the group of academics by using reflexive photography. Previous studies of academics' work experiences (e.g. their job satisfaction) tended to be pen-and-paper surveys (Oshagbemi 1996 and 1999; Fernández and Mateo 1993; Olsen, Maple and Stage 1995). Such a positivistic approach does not give participants an opportunity to articulate the many and varied issues that fashion their perceptions of their work lives. Although enquiries can involve implementing open-ended interviews, these rest on the assumption that the researcher will ask meaningful questions. Often, this is more easily desired than achieved. This research therefore aims to offer a novel approach to studying peoples' feelings and perceptions (i.e. reflexive photography).

According to Prosser (1998), image-based research is undervalued and under-applied by qualitative researchers. Prosser and Schwartz (1998), on the other hand, feel that it can make a valuable contribution to research practice and presentation. Hence, the specific research objectives of this study were to: (a) determine the usefulness of reflexive photography to illustrate how a group of white male academics experienced their work environment; (b) how the participants experienced the technique; (c) what could be identified as the advantages and limitations of the technique; and (d) how useful content analysis of the photographs are.

\section{HISTORY}

Reflexive photography as a technique was inspired by the work of Paulo Freire and his use of 'coded situations' (photographs or sketches) to stimulate members of a group to critically analyse their own situations. Amongst other things, photographs set off a kind of chain reaction that causes people to do and think things they have forgotten (or see things they have always known) in a new way (Banks 2001; Perka, Matherly, Fishman and Ridge 1992).

Harper (1988) relates the history of using photography in the social sciences. Between 1896 and 1916 photographs were used for research purposes and, during this time, 31 articles that used photographs as evidence appeared in the American Journal of Sociology. By 1920 photographs had largely disappeared from sociological publications and during the 1930s documentation by means of photographs grew largely outside the university.

In anthropology, the picture was brighter. Margaret Mead and Gregory Bateson did pioneering work with the aid of photography. However, the domination of research by means of quantitative methods between the 1920s and the 1980s meant that little progress was made with the technique. In the 1960s turmoil in society over issues such as war, class, race and gender led to conflict theory which led to several research programmes that found photography useful. However, Prosser (1998) concludes that image-based research still played a minor role in qualitative research. 
Since then, the popularity of using photography has grown. Recently, Banks $(2001,2)$ noted the popularity of visual anthropology. Hence, a number of master's degrees in visual anthropology have been developed in Britain and elsewhere. Visual sociology is also a relatively well-established sub-discipline. However, electronic searches indicate that in other fields of the human and social sciences (e.g. in education), the method has remained peripheral. This article therefore aims to fill this void. It should be noted that the article does not primarily aim to explain the work experiences of white male academics (since these will be reported in a separate article), but seeks to highlight the usefulness of the technique of reflexive photography.

\section{THEORETICAL FRAMEWORK}

Two theoretical understandings provide the basis for using reflexive photography: individual-environmental interaction theories and symbolic interactionism. Lewin (in Harrington and Schibik 2003) postulates that individual behaviour is a function of the interaction between individuals and their environment. Theories on individualenvironment interactions include physical models (noting the importance of physical environments), human aggregate models (indicating the significance of relations with colleagues) and perceptual models. Personal and collective perceptions of an institution are crucial to understanding individuals' actions and reactions in their particular environments.

The theory of symbolic interactionism (Lewin in Harrington and Schibik 2003) emphasises the meanings that individuals ascribe to symbols and things through, and as a function of, their social interactions. Herbert Blumer (in Wikipedia, the free encyclopedia, 2) coined the term and set three basic premises of the perspective: (a) Human beings act toward things on the basis of the meanings that the things have for them. (b) The meanings of such things are derived from the social interaction the person has with others. (This happens by means of language.) (c) These meanings are modified through the individual's interpretation of the things that are encountered. (Thought is therefore a core principle of the theory.)

The abovementioned illustrates that interactionists focus on the subjective aspects of social life. Human beings are seen as pragmatic actors who continually adjust their behaviour to the actions of others by interpreting them (i.e. to denote them symbolically). People and their actions are treated as symbolic objects. Adjustment is possible because of our ability (a) to imaginatively rehearse alternative possibilities of action before acting, and (b) to think about and to react to our actions and ourselves as symbolic objects. Thus humans are viewed as active, creative participants who construct their social worlds (Blumer, Garfinkel and Goffman in McClelland 2000, 1). Interactionists focus on the changeable, continually readjusting social processes and the roles people play in these.

In view of the above, reflexive photography is seen as appropriate to study the meaning that white, male academics attach to their everyday lives in a continuously changing 
academic institution and their adjustment to this. In reflexive photography participants use photographs as symbols to illustrate the subjective meaning of the things (people, physical environments, support services, etc.) in their working lives.

Reflexive photography has been used in qualitative research in two distinct ways: as images produced by researchers and as images produced by participants (Denzin and Lincoln 1994). The usefulness of both methods for research in the human and social sciences is highlighted briefly in the next section and serves as background to this study.

\section{VISUAL ETHNOGRAPHIES}

When the participants comment on the photographs that were taken by the researchers, the identification and reading of the photographs are used as the 'can-opener' or 'golden key' to human settings while the participants are put in the role of experts who teach the researchers (Collier 1967). In three examples of such projects, the aims were a needs assessment of rural women in Burundi, East Africa (Aubel 1986); the perceptions of Latina women on the quality of the prenatal care they received (Bender, Harbour, Thorp and Morris 2001); and the perceptions of street children on the career opportunities of children who live in poverty (Weinger 1998). In all three examples, the participants were disadvantaged and relatively powerless cultural groups.

Regarding the Burundi women: Photographs were taken in the area where the study was conducted, showing women and children doing typical tasks (agricultural and domestic work; caring for children, etc.). Locals who could speak the language interviewed groups of women. They showed them the pictures and asked various questions to determine their problems. The study documented the enthusiasm with which the women shared their ideas.

In the study with the Latina women, seven photographic prompts of a prenatal visit to a clinic were used. By requesting the women to describe each photograph and how the woman in the photo was feeling, the researchers were able to ascertain how the women experienced prenatal visits and what their problems were. The photographs evoked different and more compelling stories than those elicited by a questionnaire which was used in the same study.

In the project with the street children, 24 children between the ages of five and 13 years were shown two photographs. One photograph depicted a run-down home, while the other showed a suburban-type ranch home with a manicured lawn. The photoelicitation interviews were successful in determining that children who are living in poverty have restricted perceptions of their potential careers.

However, Banks (2001) states that to do visual things to participants is only meaningful within positivist research paradigms. In non-positivist, postmodern paradigms participants are recognised as equal partners and collaborators in the research process. When participants take the photographs, they define the scope of analysis by identifying the issues themselves. This procedure is less directive than traditional interviews and 
the influence of research bias is minimised (Ferketich, Phillips and Verran in Bender, Harbour, Thorp and Morris 2001).

Examples of studies that used participant generated photographs include those by Perka et al. (1992), Hanna, Jacobs and Guthrie (1995), Monteiro and Dollinger (1998) and Harrington and Schibik (2003). In the Perka et al. (1992) study, three AfricanAmerican and three white Greek undergraduate students were given a camera with a 24-exposure roll of film. The instruction was: 'Show us what State University means to you'. The photographs were analysed for content and meaning. The method was successful in illustrating how minorities were similar and different to other students in how they experienced the university.

In the Hanna et al. (1995) study, adolescent diabetics were asked to photograph situations of health and to write about how the photographs demonstrated health. The technique enabled the adolescents to communicate their feelings and ideas on the issue.

The Monteiro and Dollinger (1998) study used Ziller's autophotography method to do a qualitative analysis of 20 street children's photographs that depicted their perceptions of themselves and their environment. When the content of the approximately 200 photographs was analysed, researchers were able to identify the main themes in the lives of the children. The technique humanised a group that is often described in stereotypical ways or is dehumanised by statistics.

The Harrington and Schibik (2003) study focussed on the freshman-year experience. Ten first-time, first-year students were requested to take 27 photographs and to record their thoughts on why these were taken. After photo-elicitation interviews, the researchers concluded that the method provided them with concrete examples of what affects freshmen and offered little possibility of misinterpretation.

\section{PHOTO-ELICITATION INTERVIEWS}

Ruby $(1995,5)$ points out that images have no intrinsic meaning. Participants assign different meanings to the pictures they take and have to explain these during photoelicitation interviews. Photographs are then used to invoke comments, memory and discussion. 'As the informant studies images of his or her world and then talks about what elements mean, the interview produces information that is more deeply grounded in the phenomenology of the subject' (Harper 1988).

Bender et al. (2001) and Collier (1967) state that photographic feedback creates a state of awareness and evokes emotional feelings that lead the interview into the heart of the research. Photographs sharpen the memory, give interviews immediate character and help to keep them focused.

Photo-elicitation interviews are non-threatening because participants express themselves through an interpersonal and socially acceptable communication medium. Thus sensitive information may be tapped in this way. The awkwardness that an interviewee may feel from being put on the spot or from silences can be lessened by the presence 
of photographs. Direct eye contact need not be maintained since both parties turn to photographs as a neutral third party (Collier in Banks 2001; Cronin 1998; Kraus in Perka et al. 1992).

Photo-elicitation interviews are effective in focus groups and in low-literacy environments. Interviewees can project their own experiences onto photographs and interviews. Thus, it reveals unconscious perceptions individuals hold about their social and psychological environment. This provides insight into how people perceive and organise their worlds (Aubel 1986; Collier 1967; Kraus in Perka et al. 1992; Damico in Perka et al. 1992).

The content of photographs can also provide useful data. Bogdan and Biklen (in Perka et al. 1992) state: 'Photographs, which provide strikingly descriptive data, echo Hines' suggestions that images are more telling than words'. Although photographic data can be translated into statistics, this presents a special challenge since one image can contain numerous references (Collier 1967).

With the aforementioned as background, this study set out to determine the usefulness of reflexive photography in an educational context. An explanation of how the research was conducted will now follow.

\section{METHOD}

\section{Sample}

A sample of eight white, male academics from the human sciences of a distance education institution was purposefully selected. Since I was from the same institution and cultural group, I believe my insider status earned me the participants' trust. The men's ages ranged from 38 to 52. Two were full professors, one was an associate professor, four were senior lecturers and one was a lecturer. They had between 13 and 20 years of experience at the institution.

\section{Steps followed in the research process}

Meetings were arranged with the participants in their own offices during which the aims of the project were explained. Individual participants were provided with a camera, which was preloaded with 12-exposure film, and requested to take pictures of what they felt were the most significant aspects of their work. This had to take place within one week. The participants were assured that they could capture an object that symbolised an issue which they wanted to include. They were also requested to take notes of their reasons for including the pictures they chose. (It should be noted that the first participant was given a 24-exposure film but he recommended the use of a 12-exposure film.) A still camera was chosen because these cameras are light, cheap and relatively sturdy; and their technical operations are familiar.

Directly after processing the films (which generally took one hour) photo-elicitation interviews were conducted. The interviews started with assurances of confidentiality 
and anonymity; and permission to use a tape recorder was obtained. The participants were then asked to place the pictures in order of rank into two groups, one relating to positive aspects and the other depicting negativities. A third group was sometimes formed for pictures that included both elements. Starting with the positive group, participants explained the meaning of each picture. Interviews generally lasted about one and a half hours, were tape-recorded and were transcribed verbatim.

At the end of each interview, the participants were asked (a) how satisfied or disgruntled they were with their work, (b) if there was any information that they wanted to include about their job satisfaction or dissatisfaction but could not photograph in any way, and (c) how they had experienced the technique.

\section{Trustworthiness}

The trustworthiness of the research project was addressed as follows: Since I was from the same cultural group as the participants, an atmosphere of trust prevailed. Hopefully, this was enhanced by assurances of confidentiality and anonymity. Participants kept notes of why they selected the objects in their photographs and they used these during the interviews. As already stated, the interviews were conducted in the natural setting of the university, were tape-recorded and were transcribed verbatim. Concrete, precise descriptions from the interview elaborations constituted a principle method for establishing the reliability of patterns that were found in the data. Some follow-up interviews were conducted when I needed to clarify impressions.

\section{Ethics}

Pink (2001) and Harper (1998) emphasise that ethics should be carefully considered during the taking of editorial decisions concerning images. In this article, the five images that serve as examples do not identify participants. Other ethical measures that were undertaken included informed consent from all participants. Their approval to audiotape interviews was also obtained.

\section{Analysis of the data}

The interviews were transcribed verbatim and were analysed. The themes that emerged related to the basic job elements of the academics. These were teaching, research, community service, administration, etc. The transcripts also revealed how the participants experienced the data gathering technique, whether there was anything they wanted to capture but could not, and what the advantages and limitations of the technique were.

In a second level of analysis, the content of the pictures was analysed. The participants were numbered from one to eight. The photographs of each participant were numbered accordingly at the back for identification purposes. I noted whether the picture's meaning was positive or negative (or both); what the main theme of the picture was; and whether 
the frequency of positive versus negative themes of the photographs was significant for the overall job satisfaction of each person. Next, all the photographs were physically arranged into the categories identified from the interview transcripts, namely: teaching, research, community service, etc. The analysis led to the following findings.

\section{FINDINGS}

The symbolised meaning of the photographs

\section{Teaching}

Photographs of piles of assignments on lecturers' desks, numerous files and many textbooks illustrated how overloaded the lecturers felt. Pictures of students' work were taken to indicate frustration with the poor quality of the work.

A photograph of the name of a department that lends support in the development of learning material was taken to illustrate a participant's discontent with the teaching approach that was enforced and which he believed undermined his autonomy. In contrast, the same photograph by a member of that department was used to illustrate how content he felt. The following comments of the two participants illustrate the issue:

We are forced into a mechanistic, instrumentalist approach to teaching ... policies that enforce a certain mode of teaching. No academic arguments. This is symbolic of a social construction of knowledge. This is a paradigm that stands strongly with many people. And this department for learning development ... to me they are the police that were appointed to see that we teach in a certain way. (A full professor).

This photograph illustrates how important my work is to me. It suits my interest in being a learning developer and in teaching. (A senior lecturer).

With regard to a picture of students' files, a senior lecturer vented his discontent. $\mathrm{He}$ explained that he had 18 postgraduate students who required tremendous input. The students investigated widely divergent topics, following either a quantitative or a qualitative research approach. He experienced this as extremely taxing. It prevented him from specialising. The students often did not submit work for a significant time period and thus forced him to study their work from the beginning each time they submitted chapters of their research.

On the positive side, photographs of final copies of dissertations illustrated the satisfaction the lecturers experienced when students completed their studies successfully (Figure 1).

'I had a [master's] student ... she did very well and obtained a distinction. She came from the bundu and did a concept analysis . . . highly sophisticated . . . she needed a lot of guidance, but she worked it in ... it was fantastic.' - A senior lecturer. 


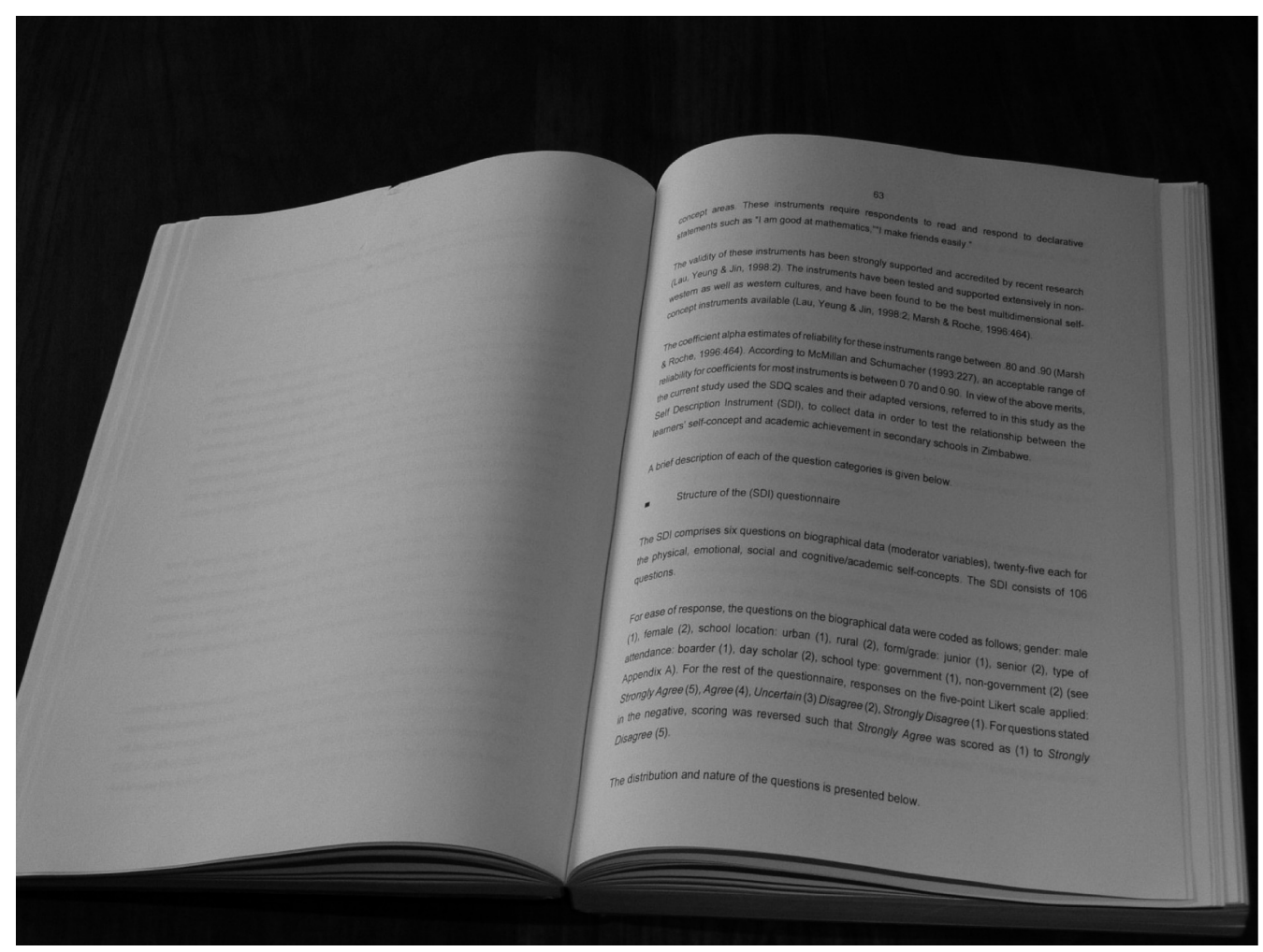

Several photographs of study guides, tutorial letters and textbooks were used to indicate satisfaction with creative work and the development of new courses. One participant photographed a messy and a neat office to indicate his appreciation of the stimulation that his diverse working environment offered. Another participant captured his bulletin board with the notice Discussion classes (which are presented twice a year). The photograph symbolised the enjoyment the lecturer experienced in having student contact.

\section{Research}

Regarding research, a photograph of a postgraduate student and a co-supervisor was used to indicate a lecturer's sense of his own inadequate research skills. Another picture of a dissertation in a dustbin symbolised how another participant viewed irrelevant research. In contrast, one photograph (Figure 2) illustrated personal satisfaction derived from embarking on meaningful research projects.

This is my own research that I am busy with. I enjoy it tremendously . . the interviews ... very interesting. It is satisfying. It is very exhausting, but I love talking to people about their perceptions of the changes in South Africa.' - A senior lecturer 


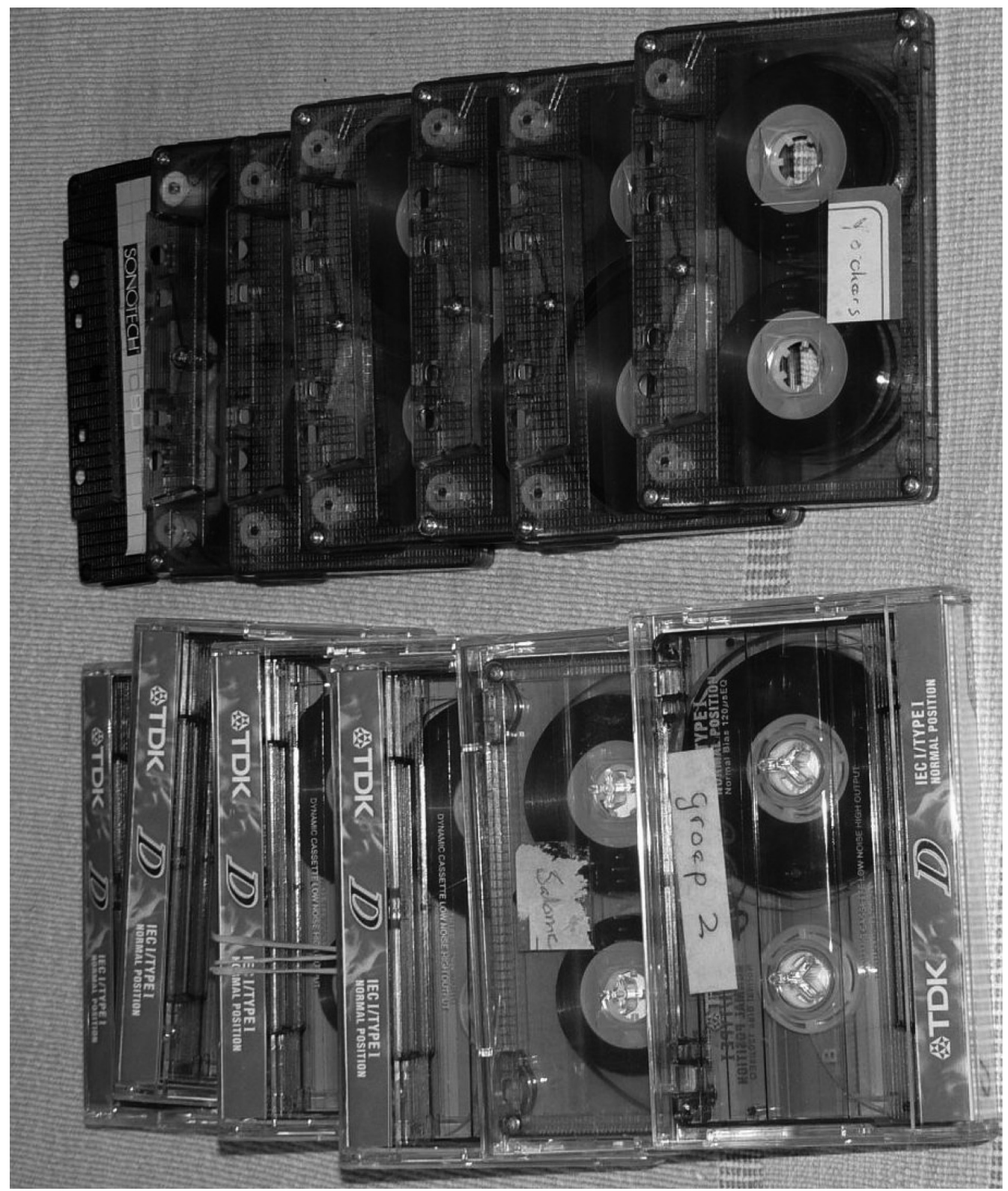

\section{Community service}

Photographs by two of the participants indicated involvement in community service projects. In contrast, a picture of vendors selling goods in the entrance hall of one of the university's buildings illustrated another's view that this is not the task of the university. The lack of other photographs relating to community service issues revealed that participants might not experience this aspect of their work as most significant. 
Administration and personal management

It is significant that the 12 pictures taken in this category were all used to vent negative feelings. Pictures of meetings or agendas and minutes of meetings symbolised participants' frustration with 'meetings, meetings, meetings' (as one exclaimed). Pointing to a picture of an electronic form on his computer screen (Figure 3), one participant observed:

This is the Higher Education Qualifications Framework, the draft for discussion. And with it is a letter stating that the curriculum should change. I want to run for miles. If I think of the agony of the previous process, I do not look forward to completing numerous forms. I think the university is a big bureaucracy that does not think about what the task of a university really is. - A senior lecturer.

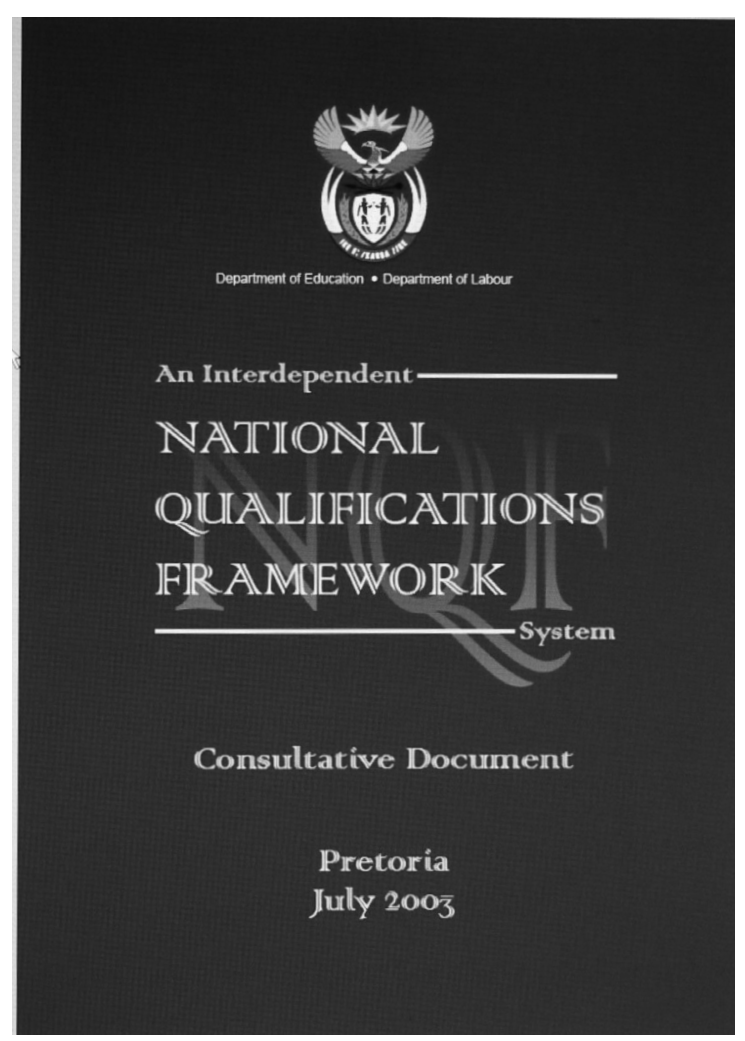

Compensation and job security

Photographs of world maps or travel documents indicated participants' satisfaction with the opportunities which the university offers for travel. 'A very, very positive aspect of my work here is the fact that I can travel overseas with my research funds', one said. Lack of job security was indicated by photographs of billboard notices of 
the university's recent merger with other HE institutions and of an agenda where one department's name was omitted after the faculty had been restructured. One participant photographed his purse (Figure 4).

Top of the list of negative issues is my salary. I think I am worth more. That's why I photographed my purse. The salary thing is a problem ... the ceiling that I have reached ... it makes me very negative.' - A senior lecturer.

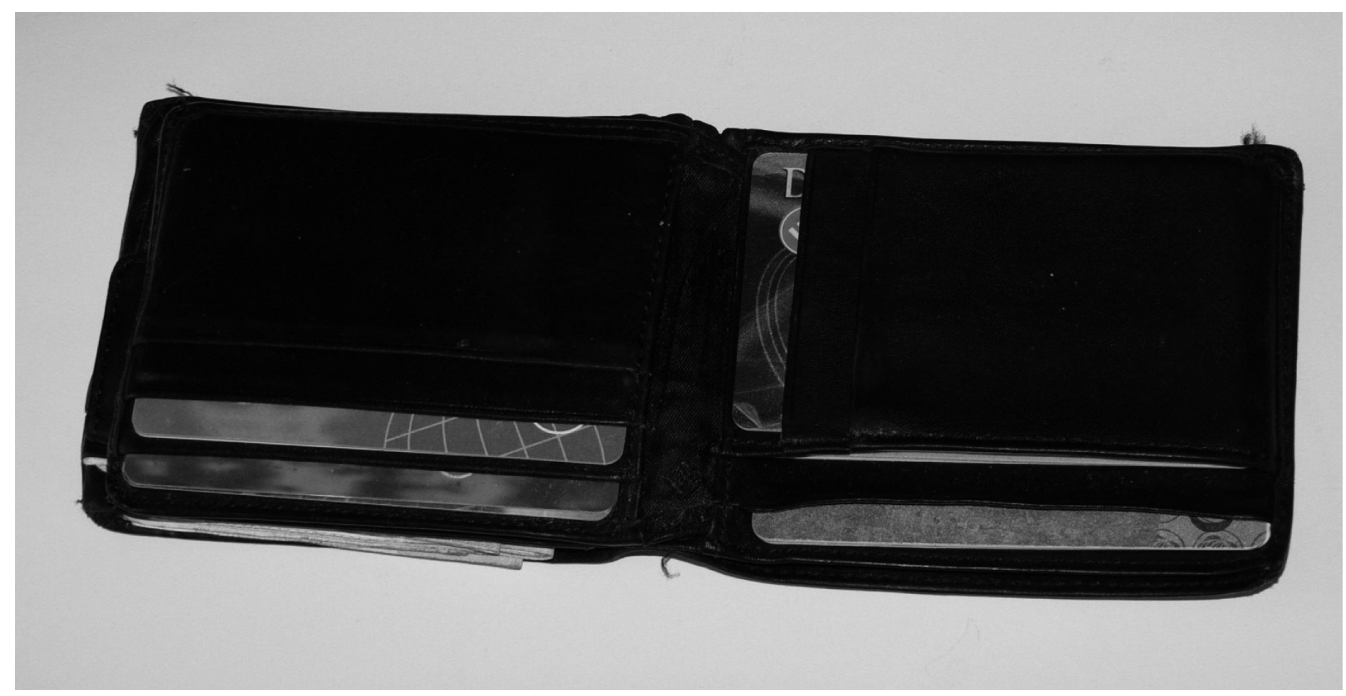

Photographs were taken of objects to symbolise different feelings about the institution's clock system for employees to register their times of arrival and departure. This allows flexible working hours. Similar pictures were used to vent positive and negative perceptions about the system (Figure 5).

The clock system runs counter to my principles. It gives a message: I don't trust you. In any case, it does not measure what it is supposed to measure. It should measure my availability to students, but most of my students meet me at home. People tell me the best way is to use it to your advantage. Clock in and do what you want and clock out when it suits you. I feel then it doesn't have any value ... it only causes bad attitudes. This is a daily fly in my soup. - An associate professor.

The clock system gives me the freedom . . . say suddenly I have to do something urgently ... go to the doctor or the pharmacy or someone calls and asks me to do something. I have freedom of time. I think this is one of the wonderful perks here. - A senior lecturer. 


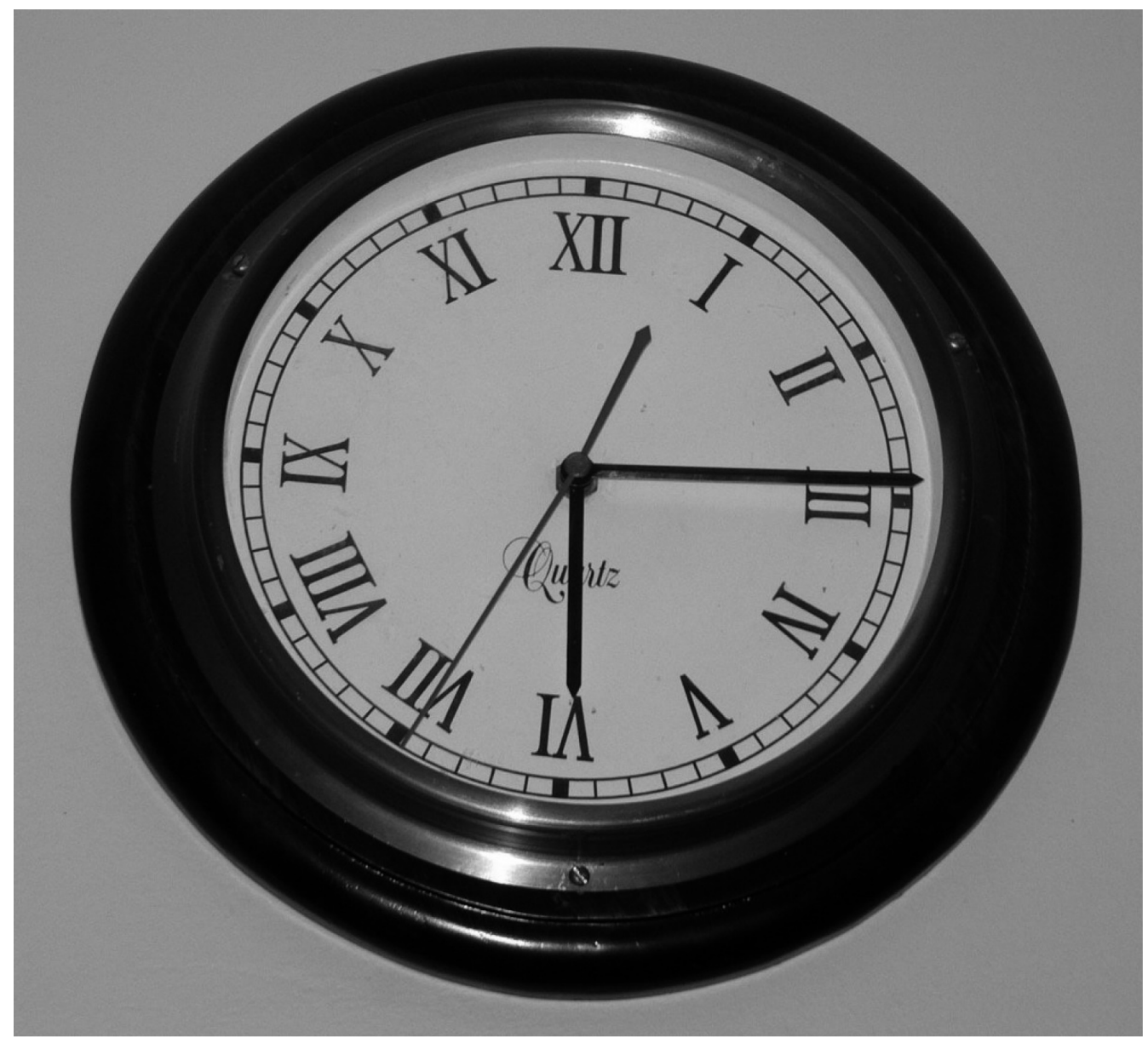

\section{Promotions}

A picture of a document with the heading Research symbolised views of promotion criteria that emphasised research. The participant said:

The teaching that you do counts for nothing. The only thing that they look at is the number of publications you have. There is no acknowledgment of anything else. Things that I do for the department are very time consuming . . . committees that I serve on, other programmes that I have developed, contracts that I handle for external markers of assignments. You don't get any credit for it. - A lecturer.

\section{Management and leadership}

In order to show his high regard for his departmental head, one participant took a picture of her nameplate on her office door. Other photographs symbolised dissatisfaction 
with the university's management and the decisions they had taken. These included a huge sign depicting the merger of the university with two other HE institutions. Another photograph showed one of the institution's top managers addressing a group of lecturers. Of this, the participant observed:

If it suits management, they are democratic . . . if it does not suit them, they are autocratic. They bring about changes of a political nature, but nothing of substance. If you ask management something, it takes two, three weeks and it is sent back. Nobody wants to take responsibility. They talk endlessly without making a decision. - A full professor.

\section{Co-workers' behaviour}

A significant number of photographs were taken of colleagues to illustrate satisfaction with interpersonal relationships. Participants said:

This photograph must give expression to the fact that I experience special fraternity with my colleagues that has led to personal friendships, the sharing of a hobby [birdwatching] ... where, if things are a bit tight at work, the support you get . . . joint work projects ... and when our work sends us together to other places . . . these become highlights of our lives. The fraternity of the people in my department more than compensates for the problems I experience here. So, if people ask me if I am happy at work, I say "Yes". - An associate professor.

You work with colleagues who are well qualified and function on a high level. It is such a privilege ... . if you need information, you can easily walk into someone else's office and enquire ... there is always someone that will know. - A full professor.

\section{Physical conditions and support facilities}

Thirteen photographs symbolised participants' appreciation of their physical environment. Photographs of offices, their views and facilities were used as symbols to indicate appreciation. Six pictures were of the institution's library. One participant attached both negative and positive meaning to similar photographs of the library, stating:

I wanted to capture the library ... what a privilege! The librarians are wonderful. I can make colour photocopies, laminate, borrow CDs . . . be trained in new techniques to access information... However, it is a pain to be pushed aside by masses of students in the library. And if you look, you will see that three quarters of the students have logged in on the Internet or are playing games. People have been appointed to ensure that the library is quiet. I cannot believe that that should be necessary! - A full professor.

In contrast, photographs were taken that symbolised discontent with perceived declining standards. One picture showed broken office furniture stacked in the corner of a small kitchen. Another photograph depicted a table with textbooks. With reference to 
this, the participant observed: 'Look at how textbooks are sold on the pavement just off campus. To me, this illustrates a lowering of standards . . a an African culture.'

\section{General}

Some pictures of campus buildings symbolised an appreciation for the institution and its stature in the community. One participant observed:

I look at the buildings and I realise that I am part of something very big. It is nice to know that the university is a place with a long history of great impact ... with certain stature and a very good infrastructure. Sometimes people from other countries are overwhelmed. It makes me feel good to realise that we deliver a service that has great impact. - An associate professor.

\section{How participants experienced the technique of reflexive photography}

When the participants agreed to take part in the research project, they were aware of what the investigation would entail. Only academics who were motivated to provide the input that was required participated. Thus, one academic declined to participate while another misunderstood the focus of the investigation and took inappropriate pictures. This data were excluded from the findings. The participants experienced the method as follow.

\section{Advantages}

All the participants experienced the technique positively and were able to express the essence of what they wanted to say. Twelve photographs were seen as adequate to symbolise perceptions. 'I feel it is an excellent way to do research . . . a photo tells a thousand words', one participant stated; while another commented on how 'interesting' it was to participate in the method: 'I had to think more than analytically; symbolically as well. I think I came closer to the heart of matters.'

The photographs facilitated venting frustrations since this was done in the third person. It was experienced as being therapeutic, which confirmed previous findings (Stuhlmiller in Kusenbach 2002).

Some participants mentioned that the method forced them to reflect and take stock of their own careers. They noted gaining insight into what was most significant in their working lives. Among other things, this happened because the technique revealed unconscious perceptions (as noted by Damico in Perka et al. 1992, 14; Harper 1988). An example is:

A photo represents and symbolises. It is the focus point and talking about it ... from there it branches into something like a mind map ... It was an eye-opener to see what I selected as first and second choice regarding my job satisfaction. I was surprised. I also see my office differently now, because I now realise that this is where I am happy. - A senior lecturer. 


\section{Limitations}

The time during which the research took place made photographing particular events (e.g. long queues of students during registration time) impossible. Sometimes a participant wanted to photograph a particular person or place but could not obtain permission to do so. This disadvantage was also noted by Aubel (1986) and Collier (1967). In these instances participants captured something that symbolised the issues they wanted to address.

I also experienced some limitations. The method was time-intensive in comparison to conducting interviews only; developing colour photographs was relatively expensive; there was a risk that the camera could get lost, damaged or stolen; analysis was more difficult than with an interview guide; and there were technical problems which meant that one photograph did not develop. This last difficulty was also encountered by Aubel (1986).

The usefulness of the content analysis of photographs

Table 1 indicates the number of positive and negative pictures and the overall job satisfaction of the participants as revealed during the interviews.

Table 1: Number of positive and negative photos and overall job satisfaction

\begin{tabular}{|l|l|l|l|l|}
\hline Participant & $\begin{array}{l}\text { Positive } \\
\text { photos }\end{array}$ & $\begin{array}{l}\text { Negative } \\
\text { photos }\end{array}$ & $\begin{array}{l}\text { Positive and } \\
\text { negative photos }\end{array}$ & $\begin{array}{l}\text { Overall job satisfaction ac- } \\
\text { cording to participant }\end{array}$ \\
\hline One & 2 & 19 & 2 & Extremely dissatisfied \\
Two & 5 & 3 & & Satisfied \\
Three & 9 & 3 & & Very satisfied \\
Four & 8 & 5 & 2 & Vatisfied \\
Five & 5 & 5 & 1 & Sery dissatisfied \\
Six & 6 & 5 & & Satisfied \\
Seven & 6 & 4 & & $80 \%$ satisfied \\
Eight & 6 & 4 & &
\end{tabular}

According to Table 1, the number of photographs with a positive or negative theme was generally indicative of overall job satisfaction or frustration. Only two participants (One and Five) described themselves as being 'very unhappy' at the institution. Although participant One took 19 pictures with a negative theme and only two with a positive theme, participant Five took an equal number of positive and negative pictures. This indicates that the relative importance of the issues depicted in the photographs is not equal. Academics assign greater importance to some aspects of their work than to others. The other participants indicated overall job satisfaction and, accordingly, each one took more pictures with a positive than a negative meaning. However, whether a photograph symbolised something positive or negative could only be revealed during the interviews. 


\section{CONCLUSION}

This study does not objectively evaluate transformation practices at an institution or the institution itself. Rather, it illustrates the usefulness of reflexive photography in qualitative research. The method revealed the subjective interpretations of the working environment of a small group of academics at one institution during a specific time period. The photographs that were taken symbolised the interpretations of the interactions of the participants with their social and physical environments. Researcher influence was minimal because the participants identified significant issues by means of the photographs which subsequently served as an interview guide.

The content analysis of the photographs had limited value, although the frequencies of positive versus negative meanings that were attached to them gave some indication of job satisfaction or frustration. The frequency with which some aspects of the work environment were captured (e.g. physical surroundings, administrative issues or colleagues) was also indicative of the relative importance of these factors. However, this analysis had to be based on a first-level analysis of the communications of participants.

Human beings are best understood in relation to their environment. Reflexive photography can aid in understanding how meaning is formed when individuals from different social and cultural groups interact with their environments. This article illustrates the usefulness of reflexive photography for qualitative research. Images inspire conversation and are recommended as a research technique in the human and social sciences.

\section{REFERENCES}

Aubel, J. 1986. My God, she has so many tasks: Listening to peasant women. Convergence XIX (2): 18-28.

Banks, M. 2001. Visual methods in social research. London: Sage.

Bender, D. E., C. Harbour, J. Thorp and P. Morris. 2001. Tell me what you mean by Si: Perceptions of quality of prenatal care among immigrant Latina women. Qualitative Health Research 11 (6): 780-794.

Collier, J. 1967. Visual anthropology: Photography as a research method. New York: Holt, Rinehart and Winston.

Cronin, O. 1998. Psychology and photographic theory. In Image-based research, ed. J. Prosser, 69-83. London: RoutledgeFalmer.

Denzin, N. and Y. Lincoln. 1994. Introduction: Entering the field of qualitative research. Handbook of qualitative research. Thousand Oaks, Calif: Sage.

Fernández, J. and M. A. Mateo. 1993. The development and factorial validation of the academic setting evaluation questionnaire. Educational and Psychological Measurement 53 (2): 425-435.

Hanna, K. M., P. M. Jacobs and D. Guthrie. 1995. Exploring the concept of health among adolescents with diabetes using photography. Journal of Pediatric Nursing 10:321.

Harrington, C. E. and T. J. Schibik. 2003. Reflexive photography as an alternative method 
for the study of the freshman year experience. NASPA Journal 41 (1): 23-40.

Harper, D. 1988. Visual sociology: Expanding sociological vision. The American Sociologist 19 (1): 54-70.

— 1998. An argument for visual sociology. In Image-based research, ed. J. Prosser, 24-41. London: RoutledgeFalmer.

Kusenbach, M. 2002. Up close and personal: Locating the self in qualitative research. Qualitative Sociology 25 (1): 149-1152.

McClelland, K. 2000. Symbolic interactionism. Available at: http://web.grinnell.edu/ courses/soc/s00/soc111-01/IntroTheories/Symbolic.html. Accessed on 2006/08/22.

Monteiro, J. M. C. and S. J. Dollinger. 1998. An autophotographic study of poverty, collective orientation and identity among street children. The Journal of Social Psychology 138 (3): 403-406.

Olsen, D., S. A. Maple and F. Stage. 1995. Women and minority faculty job satisfaction. Journal of Higher Education 66 (3): 267-293.

Oshagbemi, T. O. 1996. Job satisfaction of UK academics. Educational Management and Administration 24 (4): 389-400.

—. 1999. Overall job satisfaction. How good are single versus multiple item measures? Journal of Managerial Psychology 14 (5-6): 388-403.

Perka, P. L., C. A. Matherly, D. E. Fishman and R. H. Ridge. 1992. Using photographs to examine environmental perceptions of African-American and white Greek members: A qualitative study. College Student Affairs Journal 12 (1): 7-16.

Pink, S. 2001. Doing visual ethnography: Images, media and representation in research. London: Sage.

Prosser, J. 1998. The status of image-based research. In Image-based research, ed. J. Prosser, 97-112. London: RoutledgeFalmer.

Prosser, J. and D. Schwartz. 1998. Photographs within the sociological research process. In Image-based research, ed. J. Prosser, 115-130. London: RoutledgeFalmer.

Ruby, J. 1995. Secure the shadow: Death and photography in America. Cambridge, Mass: MIT Press.

Weinger, S. 1998. Children living in poverty: Their perception of career opportunities. Families in Society: The journal of Contemporary Human Services 79 (3): 320330.

Wikipedia, the free encyclopedia. 2006. Symbolic interactionism. Available at: http:// en.wikipedia.org/wiki/Symbolic_interactionsim. Accessed on 2006/08/22. 